\title{
IMPACTING PRACTICE THROUGH IB SCHOLARSHIP: TOY RECALLS AND THE PRODUCT SAFETY CRISIS
}

\author{
Hari Bapuji ${ }^{1}$ \\ Faculty of Business and Economics \\ The University of Melbourne, Victoria 3010 Australia \\ E-mail: hari.bapuji@unimelb.edu.au \\ Phone : +61-3-8344-9867 \\ Paul W. Beamish \\ Ivey Business School, Western University \\ 1255 Western Road, London, Ontario, Canada N6G 0N1 \\ Email: pbeamish@ivey.ca
}

May 12, 2019

\section{ACKNOWLEDGEMENTS}

The authors would like to thank the editor and three anonymous reviewers for improving this paper with their insightful comments. Numerous others, particularly a number of managers, regulators, and academic colleagues played an important role in this research by freely and generously offering their time and expertise. Our sincere thanks to them.

\section{Full Citation:}

Bapuji H, Beamish P. 2019. Impacting Practice through IB Scholarship: Toy Recalls and the Product Safety Crisis. Journal of International Business Studies. https://doi.org/10.1057/s41267019-00247-3

\footnotetext{
${ }^{1}$ Corresponding author
} 


\title{
IMPACTING PRACTICE THROUGH IB SCHOLARSHIP: TOY RECALLS AND THE PRODUCT SAFETY CRISIS
}

\begin{abstract}
IB research has made significant contributions in understanding MNEs, yet examples of scholarship that have had a demonstrable impact on practice and policy are rare. This article presents research we conducted in the wake of the 2007 global product safety crisis as one such example. We reflect on it to suggest that IB research can enhance its impact by focusing attention on issues that affect both MNEs and societies, and by using available data to arrive at even basic explanations and solutions to inform practice and prompt further academic research.
\end{abstract}




\section{INTRODUCTION}

IB scholarship has highlighted a number of challenges in managing operations in foreign markets, such as cultural differences, liability of foreignness, knowledge transfer difficulties, and managing joint ventures. Scholars have reviewed and noted the central role JIBS has played in facilitating this impact (Liesch, Hakanson, McGaughey, Middleton, \& Cretchley, 2011; SenoAlday, 2010; Verbeke \& Calma, 2017). While IB research enhanced our understanding of MNEs through sophisticated theorization and methods, it is often difficult to provide direct evidence of its impact on practice and policy. Therefore, scholars have called on IB researchers to engage with broader issues such as global product safety, misconceptions about FDI, and the corporate social responsibility practices of MNEs to achieve impact (Kolk, 2016; Peng \& Chen, 2011; Peng, Sun \& Blevins, 2011; Teagarden, 2009).

The quest for impact is not limited to IB research, as is evident from hundreds of articles, commentaries, and debates published in leading journals on how to bridge the rigor-relevance gap. This research stream, which aims to align theory and practice, rarely offers "examples of cases where management research has been successfully applied that could serve as models for further research" (Kieser, Nicolai \& Seidel, 2015: 185). Even the few exemplars provided do not refer to research per se and offer weak evidence (Kieser et al., 2015).

Although somewhat rare, examples of scholarship that affected practice and policy can provide a refreshing avenue for thinking about the nature, scope, and impact of IB research, as well as of management research in general. Accordingly, we present an example of research we conducted and communicated in the wake of the 2007 global product-safety crisis and its impact. Specifically, when a large number of toys were recalled in the US and the developed world, the

focus naturally shifted to their manufacturing location in China and to its then-poor institutional 
environment. While this narrative dominated the public discourse and received support from at least some in the academic community as well, it was not backed by data.

Within that context, we conducted initial research on the topic and communicated it during the time when the issue dominated the public discourse. Our research examined toy recalls in the US over a period of 20 years and showed that the vast majority of these recalls were not due to manufacturing flaws at factories in foreign countries (e.g., China), but due to design flaws that could be attributed to the company headquarters in home countries (e.g., US). This research (Bapuji \& Beamish, 2007) helped to shape public opinion, changed MNE behaviour, and had a positive impact on product-safety developments.

We begin by briefly discussing the global product safety crisis of 2007 and related IB research. We then present our research and evidence of its impact. We conclude with a discussion of how IB research can enhance its impact through scholarship that engages multiple stakeholders.

\section{PRODUCT SAFETY CRISIS AND IB RESEARCH}

Recalls of hazardous products have been common over the years, but 2007 was dubbed “The Year of The Recall” since many products made in China were recalled in the US and around the world (Bapuji, 2011 and Teagarden, 2009 provide detailed accounts of these recalls). Among these, toy recalls heightened safety concerns over products made in China.

One of the early and prominent recalls was issued by the toy company RC2, which had exclusive licenses from several high-profile US companies to produce and sell toys under their brand name (e.g., Disney). Upon learning from a US retail customer that the surface paint on a Thomas \& Friends toy contained excessive lead, RC2 conducted its own investigations and recalled 1.86 million toys produced by its contract manufacturers. In its communications, RC2 
asserted that its supplier failed to follow RC2's safety specifications. This line of defence was later adopted by toy-industry leader Mattel, which issued several recalls in 2007.

Mattel's announcement on August 14, 2007 garnered unprecedented media attention. On that day, Mattel issued a recall of 463,000 Sarge cars due to unsafe levels of lead. At the same time, Mattel announced an expanded recall of 18.2 million toys that contained small, powerful magnets that could come loose and create hazards for children. Mattel stated that the excess lead on the recalled toys was a result of one of its sub-contractors using paint from a non-authorized supplier and that Mattel implemented an enhanced check system to prevent the recurrence of the problem.

This spate of recalls severely eroded consumer confidence in products made in China, and the public made calls to boycott Chinese-made goods until the Chinese government improved its safety regulations on exported goods. Western governments were quick to respond to this crisis of confidence by cracking down on unsafe goods, particularly those designed for children (Bapuji \& Beamish, 2008a).

In an attempt to mitigate the fallout, the Chinese government set up a task force that intensified inspections of manufacturing plants, suspended or revoked the export licenses of hundreds of companies, and even jailed some suppliers. Further, Chinese authorities declared that the majority of products made in China were safe and that Western companies were making China a scapegoat, causing suppliers to close factories and lay off workers. In retaliation, China began to reject certain North American imports (Bapuji \& Beamish, 2008a).

In sum, the global product safety crisis of 2007 placed China and its manufacturing under global pressure and introduced a threat to trade and international business. 


\section{Our research}

Our involvement with this research began with media requests for comments on the recalls and their impact on China and Western MNEs. Our initial engagement was driven by a willingness to participate in the broader discourse and to derive possible implications for teaching IB. As such, we followed the tradition of IB research to examine issues arising from empirical developments in the world economy (Buckley, 2002). For numerous reasons, the developments described above ran counter to our IB research-based understanding and thus posed a puzzle.

First, previous research showed that consumers in developed countries had a bias against the products made in developing countries (Bilkey \& Nes, 1982), and MNEs generally strove to mitigate that bias in order to secure their own ongoing manufacturing advantages. So, it was surprising to see MNEs point to Chinese manufacturing as the problem, thus endangering future arbitrage opportunities.

Second, MNEs choose to locate their manufacturing in a particular country in order to exploit advantages of firm ownership, country location, and firm internalization (Dunning, 1998). In particular, after China joined the WTO, US toy companies took advantage of China's lower production costs and leveraged their assets (e.g., R\&D, product designs, brands). Although this development occurred in other industries, only toy recalls materially increased, which suggested that the recalls were due to peculiarities within the toy industry itself and not to evolving global production systems.

Third, since most toys are simple products that do not involve complex knowledge and design, many US toy companies have long engaged contract manufacturers without facing substantial risks (Kogut \& Zander, 1993). Thus, it seemed unlikely that the product recalls were 
a result of companies engaging in a mode of production that was unsuited to the nature of the product or one in which they were inexperienced.

Fourth, similar to licensing arrangements, when they outsource manufacturing, MNEs provide numerous detailed, non-negotiable technical specifications and manufacturing instructions in their contracts (Beamish \& Webb, 1988). Any failures on this account will result in the rejection of goods, imposition of penalties, and even cancellation of contracts. Therefore, suppliers' failure to follow specifications seemed an unlikely reason for the massive surge in recalls. Further, the distribution of value chain activities within an MNE and to its suppliers is highly complex, so errors could have occurred in any part of the value chain - within the MNE, with a supplier, or both.

Finally, Mattel had decades of experience with offshore manufacturing and a reputation for not facing supply-chain defects before then (Barboza \& Story, 2007). So, we were puzzled by its assertions of supplier malpractice. Also, Mattel blaming its longstanding contractors seemed peculiar because repeated transactions enhance trust levels and thus, partners protect each other (Dyer \& Chu, 2000).

In sum, the 2007 product recalls and the assertions of toy companies - and particularly Mattel's - did not pass the smell test. Moreover, the discourse was characterized by anecdotal evidence and lacked systematic empirical support. Therefore, we decided to examine the available data on recalls and to closely scrutinize Mattel's recalls.

Using data from the U.S. Consumer Product Safety Commission (CPSC) website, we analyzed 550 recalls (from 1988 to mid-2007) by noting the total number of recalls in each year, the number of recalls that involved toys made in China, and the type of flaw that caused the 
recall. We coded each flaw type into two categories: design flaw or manufacturing flaw (Beamish \& Bapuji, 2008 provide description of the data, coding procedure, and its reliability).

We found that toy recalls increased in the few years leading up to 2007 and, indeed, many of the recalled toys were made in China. However, only $10 \%$ of the total recalls were due to manufacturing problems, while $76 \%$ were due to design flaws that could have been prevented by the toy companies themselves. The information in the recall notices was not adequate to classify the remaining $14 \%$. Incidentally, this first analysis inadvertently missed 49 toy recalls (less than 10 per cent) during the data collection. However, subsequent analyses using the expanded and extended samples showed that the original conclusions were quite robust.

In examining Mattel's recalls, we pointed out that $90 \%$ of the recalled units suffered from design flaws, for which Mattel had sole responsibility. The other $10 \%$ were due to excess lead in paint, a problem that could have been prevented with better governance by Mattel. Thus, we suggested that safety in global supply chains is a shared responsibility between MNEs and their suppliers and that Mattel had mischaracterized the recalls and avoided taking responsibility for its role in them.

Our report (Bapuji \& Beamish, 2007) was published by the Asia Pacific Foundation of Canada, a government-funded, independent think-tank that focuses on relations between Canada and the Asia-Pacific Region. We made the report freely available to the media and general public. This report and our later works on the topic shaped the discourse and influenced practice and policy.

\section{EVIDENCE OF IMPACT}

Our initial research received a great deal of attention from media, practitioners, regulators, and policymakers; it also inspired our own subsequent research. We present a 
summary of this evidence in Table 1 and elaborate in the following paragraphs.

Table 1

\section{Mattel's admission, apology, and clarification}

In the one week following the publication of our study, its findings and our views were reported widely by media outlets around the world and were also discussed at the conclusion of the Biennial Sino-US Consumer Product Safety Summit between the CPSC and China's General Administration for Quality Supervision, Inspection and Quarantine (AQSIQ).

On September 21, 2007 (i.e., two weeks after the publication of our study), Mattel abruptly backtracked on its earlier assertions and apologized to the head of AQSIQ, stating that "Mattel takes full responsibility for these recalls and apologizes personally to you, the Chinese people, and all of our customers who received the toys." Mattel went on to say that the product recalls were the result of flaws in Mattel's design and were not due to problems with the Chinese manufacturing (Story, 2007). After that announcement, our study received heightened media attention, including several requests for interviews and citing of our study in news reports covering Mattel's apology.

It seems reasonable to infer that Mattel apologized because of the surge in media attention to its failure to mention its own design flaws, as our study pointed out, but we cannot rule out alternative explanations. Therefore, to address this question, we performed a content analysis of the media coverage of Mattel's apology using NVivo software (see Online Appendix). This analysis revealed that the stakeholders felt that the apology was due to Mattel's mismanagement of the crisis (including its failure to admit its role in the crisis) and to mend 
fences with Chinese stakeholders by undoing the damage made to China's reputation, given Mattel's dependence on China for manufacturing.

Although Mattel's economic dependence on China and its frayed relations with the country were contributing factors, it is possible that our study and its discussion in the media had the effect of weakening Mattel's position and paving the way for the Chinese authorities to legitimately demand remedial action from Mattel. This is because our study contributed to shifting the discourse on the reasons for recalls and gave credence to some of the arguments made by Chinese authorities.

\section{A broader shift in discourse}

To examine the change in discourse and the role our research played in it, we conducted additional analysis (see Online Appendix) on the media coverage of 'toy recalls' one year before (before-period) and one year after the publication of our study (after-period). This analysis revealed that the word design occurred four times more frequently in the after-period than in the before-period. To further ascertain that this increased usage was reflective of a broader shift in the discourse, we analyzed the titles of the newspaper articles for word usage and sentiment. We noted that the vocabulary used in the titles became more diverse in the after-period relative to the before-period, and the tone of discussion became more positive and balanced in the after-period, particularly in reference to China.

Specifically examining the most used words, we found a reduction in discussions of factories, lead, and magnet toys in the after-period. Also, references to design were limited in the before-period, but were more expansive and wide-ranging in the after-period, i.e., clarified design flaws as reasons for recalls, discussed the need to improve designs, and reported the steps taken by MNEs to improve designs. Finally, all design references to research, study, and 
university were connected to our research, thereby confirming that only our research, and not any other research, had likely contributed to the shift in the discourse.

While the specific nature of our research related to mischaracterization of recalls by MNEs, our broader arguments focused on the shared responsibility of various partners in the global supply chain to improve product safety. Since the publication of our findings, media articles often identified this shared responsibility and clarified the locations of a given product's design and manufacture. Additionally, in its recall notices, the CPSC began to include precise information on the supply chain partners involved in the manufacture and sale of the recalled products.

To the best of our knowledge, we were the first researchers to use data from the CPSC to examine historical trends and advocate for an evidence-based approach to improving product safety (Beamish \& Bapuji, 2008). Although we certainly cannot attribute the following changes to our research alone, we have noted that, following the recalls crisis of 2007, CPSC and other agencies placed increased attention on their data, making it more expansive, better organized, and more user-friendly, while companies started to create recall indexes similar to those in our research.

Overall, the evidence presented above suggests that our research had at least some impact. Specifically, it helped to shape public discourse on global product safety, influenced MNEs to focus on improving designs, and informed policy and practice to focus on shared responsibility. Reflecting on this research and our personal experience, we derive some implications for IB research and the literature on conducting impactful research in the next section. 


\section{DISCUSSION}

In its 50 years of existence, JIBS has published over 1,700 research articles and made a considerable impact on IB research, and thus, on practice. This special issue provides an opportune moment to reflect on IB scholarship and its impact. Our selection of this work for reflection is not due to its academic impact, but rather to the greater impact it had on practice and policy.

A growing body of literature exists on how to conduct impactful research, but this stream contains few examples of research that has actually achieved impact. Even the examples presented usually focus on the mechanics of achieving impact (e.g., partnerships and collaborations with industry), or do not offer evidence that directly traces the impact to the research in question (Kieser et al., 2015). Accordingly, we offer our own example as a discussion vehicle on conducting impactful research. In the remainder of this section, we dwell on the implications of our study to conduct impactful research.

\section{Conducting Impactful IB scholarship}

Some scholars suggest that better infrastructure is needed to translate academic research to achieve impact (Shapiro, Kirkman \& Courtney, 2007). Our experience suggests that a more fundamental problem may lie in identifying useful areas of inquiry of immediate and direct relevance to managers. To that end, focusing on real-world phenomena that sit at the intersection of business and society (e.g., escalating economic inequality, rising economic nationalism, tax avoidance by MNEs) and attempting to dissect and explain these issues could be a good first step towards conducting IB research that will have pluralistic impact, i.e., impact not only on research and practice, but also on education and policy (Aguinis, Shapiro, Antonacopoulou \& Cummings, 2014; Doh, 2017). 
While focusing on a phenomenon is important, it is equally important to examine its micro-foundations and identify the factors that give rise to the phenomenon and the interrelationship between them (Abell, Felin \& Foss, 2008). We believe our research achieved some impact because it dug deeply into the issue of product recalls, seeking the reasons behind them and suggesting improvements to current recalls-related practices. Therefore, among other areas, scholars aiming for impact may strive to theoretically and empirically examine phenomenon at the intersection of business and society to uncover its antecedents, address its consequences, and offer solutions.

Our experience suggests that conducting impactful research may require adopting an approach that differs from traditional research practices. For example, while most academic research begins with an attempt to fill a gap in our understanding and theory, our own engagement in the product-recall stream began as an exercise to explore a real world IB phenomenon. And, we did not have the benefit of past IB research focused on product recalls. Further, unlike regular research that uses established archival datasets and employs sophisticated analytical techniques, we used hitherto unused, but publicly available data from the CPSC to conduct arguably simple analysis. While most academic research takes months and years to conduct and communicate, the time from our initial engagement with this issue to the publication of our first report was only three weeks. Finally, this experience also shows that to achieve a pluralistic impact, scholars may have to write different pieces for different audiences (e.g., academic papers in top-tier journals (Carvalho, Muralidharan \& Bapuji, 2015; Hora, Bapuji \& Roth, 2011), managerial articles (Bapuji \& Beamish, 2008c), policy focused papers (Bapuji \& Morris, 2011), teaching cases (Bapuji \& Beamish, 2008a; 2008b), and op-eds) and also use other 
modes to communicate the findings (e.g., media interviews, presentations to and discussions with stakeholders, and making videos).

Although we had to expend substantial time and resources on communicating research findings, it had the added benefit of identifying new research questions and generating academic impact. For example, stakeholder interactions helped us offer further nuance on imports and recalls (Bapuji, Beamish \& Laplume, 2007) and identify new areas of academic inquiry, such as time to recall and recall remedy (Hora et al., 2011; Muralidharan, Bapuji \& Hora, forthcoming). As a result, our research had academic impact (e.g., 411 citations on Google Scholar; Hora et al., (2011) is one of the most cited papers on product recalls) and also won appreciation for its quality (e.g., Beamish \& Bapuji (2008) was selected for a global campaign by the Operational Research Society and Wiley-Blackwell; Bapuji (2011) was selected by CHOICE Magazine as an Outstanding Academic Title). In short, we find an interactive complementarity between engagement with stakeholders and traditional academic research aimed at peer-reviewed journals.

\section{Scope and stakeholders of IB research}

By addressing issues of global importance, IB scholarship has always been an exciting field. Yet, leading scholars have raised questions about the domain, scope, and impact of IB scholarship (Buckley, 2002). To enhance the impact of IB research, scholars suggested examining the grand challenges of society (Buckley, Doh and Benischke, 2017). However, systematic analyses of IB research have shown that over time IB research has shifted away from a more macro-orientation to a focus on firm-level behaviour (Liesch et al., 2011).

To realize the potential impact that IB scholarship can make, it is important to reflect on what IB research is, how it is conducted, who its stakeholders are, and thus, what impact is. First, 
a focus on MNEs while no doubt important, might lead scholars to avoid issues at the intersection of the MNE and society. For example, although global supply chains and slippages in them concern MNEs, IB scholarship has paid limited attention to it, as evidenced by the sparse number of publications on the topic in IB journals. Second, premier journals increasingly value nuanced theorization and sophisticated methods utilizing large and established datasets. While important, they may not always be amenable to engaging with big and/or emerging questions, thus confining such engagement to non-academic outlets (e.g., Contractor, 2017). Third, an emphasis on theoretical contribution and rigor limits the audience for most research to fellow academics, and excludes stakeholders less interested in theories and methods. Therefore, to realize the impact IB research can make to improving societies through globalization, it is necessary to consider other stakeholders of international business and engage with them. Finally, research impact is often measured by the outlets in which the research appeared or the number of citations it had received. While these are useful indicators of impact, they do not fully capture the impact made through education and via the shaping of practice and policy. Given the breadth of issues that IB scholars examine and the many ways in which MNEs impact the lives of individuals, it is sometimes necessary to look beyond citations and journal impact factors to value and encourage research that attempts to influence practice and policy.

In presenting this study as an example of impactful IB scholarship, we have addressed a few limitations of previous exemplars. Yet the impact we presented is not based on a peerreviewed journal article (Kieser et al., 2015), and to that extent, the lessons we can draw are somewhat limited. Relatedly, we should also note that in no way are we advocating the abandonment of rigor or peer-review. Rather, our example emphasizes the value that academics can bring to practice and policy by pursuing rigorous, data-driven research. We say this because 
although our study was not published in a peer-reviewed journal, it made use of over 20 years of systematic and reliable data on toy recalls.

In conclusion, rigorous, peer-reviewed research might not achieve an immediate and direct impact on practice, but it creates knowledge and enhances our understanding. Similarly, research that makes an immediate and direct impact on practice might not fully meet the standards of rigor and peer-review necessary for academic impact. Therefore, the challenge lies in appreciating the value of both modes of inquiry so that each can reflect and learn from the other to conduct research that can build better businesses and societies. 


\section{References}

Abell, P., Felin, T., \& Foss, N. 2008. Building micro-foundations for the routines, capabilities, and performance links. Managerial and Decision Economics, 29(6): 489-502.

Aguinis, H., \& Shapiro, D., Antonacopoulou, E., \& Cummings, T. 2014. Scholarly impact: A pluralist conceptualization. Academy of Management Learning \& Education, 13(4): 623 639.

Bapuji, H., \& Beamish, P. 2007. Toy recalls: Is China really the problem? Canada-Asia Commentary, September. Asia Pacific Foundation of Canada.

Bapuji, H., Beamish P., \& Laplume A. 2007. Toy import and recall levels: Is there a connection? Research Reports, November. Asia Pacific Foundation of Canada.

Bapuji, H., \& Beamish, P. 2008a. Mattel and the toy recalls. Case A. Ivey Publishing. 9B08M010.

Bapuji, H., \& Beamish, P. 2008b. Mattel and the toy recalls. Case B. Ivey Publishing. 9B08M011.

Bapuji H., \& Beamish P. 2008c. Product recalls: Avoid hazardous design flaws. Harvard Business Review. March: 23-26.

Bapuji, H. 2011. Not just China: The rise of recalls in the age of global business. Palgrave Macmillan: New York.

Bapuji H., \& Morris K. 2011. Consumer product safety in Canada: From enacting to acting. Policy Options. April: 48-50.

Barboza D., \& Story L. 2007. Toymaking in China, Mattel's way. New York Times. July 26.

Beamish, P., \& Bapuji, H. 2008. Toy recalls and China: Emotion vs. evidence. Management and Organization Review, 4(2): 197-209.

Beamish, P., \& Webb, W. 1988. Note on international licensing. Ivey Publishing. 9A88G001.

Bilkey, W.J., \& Nes, E. 1982. Country-of-origin effects on product evaluations. Journal of International Business Studies, 13(1): 89-100.

Buckley, P. J. 2002. Is the international business research agenda running out of steam? Journal of International Business Studies, 33(2): 365-373.

Buckley, P. J., Doh J. P., \& Benischke M. H. 2017. Towards a renaissance in international business research? Big questions, grand challenges, and the future of IB scholarship. Journal of International Business Studies, 48(9): 908-921.

Carvalho, S., Muralidharan, E., \& Bapuji H. 2015. Corporate social 'irresponsibility': Are consumers' biases in attribution of blame helping companies in product-harm crises involving hybrid products? Journal of Business Ethics, 130(3): 651-663.

Contractor, F. J. 2017. Global leadership in an era of growing nationalism, protectionism, and anti-globalization. Rutgers Business Review, 2(2): 163-185.

Doh, J. 2017. Phenomenon-based research in international business: Making IB relevant again. AIB Insights, 17(2): 14-16.

Dunning, J.H., 1998. Location and the multinational enterprise: a neglected factor? Journal of International Business Studies, 29(1): 45-66.

Dyer, J.H., \& Chu, W. 2000. The determinants of trust in supplier-automaker relationships in the US, Japan and Korea. Journal of International Business Studies, 31(2): 259-285.

Hora M., Bapuji H., \& Roth A. 2011. Safety hazard and time to recall: The role of recall strategy, product defect type, and supply chain player in the U.S. toy industry. Journal of Operations Management, 7-8: 766-777.

Kieser, A., Nicolai, A., \& Seidl, D. 2015. The practical relevance of management research: 
Turning the debate on relevance into a rigorous scientific research program. Academy of Management Annals, 9(1): 143-233.

Kogut, B., \& Zander, U., 1993. Knowledge of the firm and the evolutionary theory of the multinational corporation. Journal of International Business Studies, 24(4): 625-645.

Kolk, A. 2016. The social responsibility of international business: From ethics and the environment to CSR and sustainable development. Journal of World Business, 51(1): 2334.

Liesch, P. W., Hakanson, L., McGaughey, S. L., Middleton, S., \& Cretchley, J. 2011. The evolution of the international business field: A scientometric investigation of articles published in its premier journal. Scientometrics, 88(1): 17-42.

Muralidharan E., Bapuji H., \& Hora M. Forthcoming. The more I err, the less I pay: Effect of firm recall experience, firm type, and recall severity on remedy to consumers. European Journal of Marketing. https://doi.org/10.1108/EJM-12-2017-0964

Peng, M.W., \& Chen, H. 2011. Strategic responses to domestic and foreign institutional pressures: The case of the Chinese toy industry. International Studies of Management \& Organization, 41(2): 88-105.

Peng, M.W., Li Sun, S., \& Blevins, D. 2011. The social responsibility of international business scholars. Multinational Business Review, 19(2): 106-119.

Seno-Alday, S. 2010. International business thought: A 50-year footprint. Journal of International Management, 16(1): 16-31.

Shapiro, D. L. Kirkman, B. L., \& Courtney, H. G. (2007). Perceived causes and solutions of the translation problem in management research. Academy of Management Journal, 50(2): 249266.

Story L. 2007. Mattel Official Apologizes in China. The New York Times. September 21.

Teagarden, M. 2009. Learning from toys: Reflections on the 2007 recall crisis. Thunderbird International Business Review, 51(1): 5-17.

Verbeke, A., \& Calma, A. 2017. Footnotes on JIBS 1970-2016. Journal of International Business Studies, 48: 1037-1044. 


\section{Table 1: Evidence of Pluralistic Impact}

\begin{tabular}{|c|c|c|}
\hline Stakeholder & Scholarly Output and/or Evidence & Impact/Outcome \\
\hline Media & $\begin{array}{l}\text { - Findings reported globally, in } \\
\text { over } 150 \text { outlets } \\
\text { - Increased discussions on design } \\
\text { flaws }\end{array}$ & $\begin{array}{l}\text { - Helped shape the discourse on global } \\
\text { product safety } \\
\text { - Appreciation of shared responsibility } \\
\text { in global supply chains }\end{array}$ \\
\hline $\begin{array}{l}\text { MNEs/Mattel/ } \\
\text { Suppliers/Intermediaries }\end{array}$ & $\begin{array}{l}\text { - Requests for research and } \\
\text { discussions } \\
\text { - Affirmation of our findings }\end{array}$ & $\begin{array}{l}\text { - Mattel's admission of its own role in } \\
\text { recalls, and apology to China } \\
\text { - Improved attention to designs }\end{array}$ \\
\hline Industry Associations & $\begin{array}{l}\text { Requests for research and } \\
\text { multiple invitations to speak; } \\
\text { sessions attended by over } 700 \\
\text { participants. One presentation } \\
\text { livestreamed on C-SPAN }\end{array}$ & $\begin{array}{l}\text { - Evidence-based debate on recalls and } \\
\text { recall effectiveness }\end{array}$ \\
\hline $\begin{array}{l}\text { Academic community/ } \\
\text { Broader society }\end{array}$ & - 17 publications & $\begin{array}{l}\text { - } 411 \text { citations, reflecting the effect on } \\
\text { management research (e.g., IB, } \\
\text { operations management, marketing) } \\
\text { and outside (sociology, public } \\
\text { relations, public health) }\end{array}$ \\
\hline Practitioners & - Harvard Business Review article & \\
\hline Students & $\begin{array}{l}\text { - Three teaching cases } \\
\text { - Requests for research from } \\
\text { students (high school and } \\
\text { university), publication of } \\
\text { findings in Scholastic Books }\end{array}$ & $\begin{array}{l}\text { - Used by over } 50,000 \text { students in } 50 \\
\text { countries } \\
\text { - Enhanced classroom education }\end{array}$ \\
\hline Regulators & $\begin{array}{l}\text { - Request for research and } \\
\text { discussions with many regulators } \\
\text { (e.g., US, Canada, Australia, EU) }\end{array}$ & $\begin{array}{l}\text { - Improved data presentation } \\
\text { - Increased data access }\end{array}$ \\
\hline Policymakers & $\begin{array}{l}\text { - Request for research and/or } \\
\text { discussion on behalf of (i) the US } \\
\text { House of Representatives } \\
\text { Committee, (ii) two Canadian } \\
\text { Members of Parliament } \\
\text { - Testimony to The House of } \\
\text { Commons Standing Committee on } \\
\text { Health - Canada } \\
\text { - One paper in Policy Options }\end{array}$ & - Shaping of legislation and regulations \\
\hline Lawyers & $\begin{array}{l}\text { - Request for research and } \\
\text { invitations for expert testimony }\end{array}$ & $\begin{array}{l}\text { - Declined invites to testify as expert } \\
\text { witnesses }\end{array}$ \\
\hline
\end{tabular}




\section{ABOUT THE AUTHORS}

Hari Bapuji is an Associate Professor (Strategy \& IB) in the Department of Management and Marketing, Faculty of Business and Economics, The University of Melbourne, Australia. His primary research interests lie at the intersection of business and society, with a recent focus on how economic inequality affects businesses, and vice versa.

Paul W. Beamish is a Director of the International Business Institute at the Ivey Business School at the Western University in Canada. He is a Fellow of the Royal Society of Canada, of the Academy of International Business, and founder of the 39 country initiative. 


\section{IMPACTING PRACTICE THROUGH IB SCHOLARSHIP: TOY RECALLS AND THE PRODUCT SAFETY CRISIS}

\section{Online Appendix}

Our qualitative analysis used a set of 996 relevant articles published between November 2006 and October 2008 (i.e., the crisis period, which also covers one year before and after the publication of our study). We retrieved these articles by conducting a search in Lexis-Nexis for "toy recalls." We conducted content analysis using NVivo software to examine the changes in discourse following the publication and communication of our research as well as to test for alternative explanations.

\section{Mattel's Apology - Explanations}

Of the 996 news articles, we identified a set of 46 articles that mentioned Mattel's apology for further analysis. Of these, some articles simply reported on the apology at the time it was made (8 articles), some discussed it in depth (15 articles), and the rest referred to it in the period following the apology ( 23 articles). The eight articles that simply reported the apology mentioned that Mattel apologized for its own design flaws and for being over-inclusive in its lead recalls, which made the problem appear bigger than it was and thus damaged China's reputation. The later articles (23) predominantly used the apology to refer to improvements being made in China and to underscore the quality of products in China, in reporting specific recalls, and in discussing the product safety crisis and the role of MNCs in design and testing.

Media articles that discussed Mattel's apology in some depth gave multiple reasons for Mattel's decision to apologize publicly to China: (i) the apology was necessary because of Mattel's overall mismanagement, including not mentioning its own design flaws and not acknowledging its own responsibility for the safety of its imported products (20 mentions); (ii) 
the apology was an effort to mend fences with the Chinese government and suppliers, as well as to undo the damage made to China's reputation (15 mentions); (iii) the apology reflected Mattel's dependence on China as $65 \%$ of its toys were made in China (6 mentions); and (iv) the apology underscored the shared responsibility of MNCs and suppliers in ensuring quality in designs and manufacturing (2 mentions).

\section{Focus on Improving Design by MNEs and Stakeholders}

To assess how our findings influenced MNE behaviour, we returned to our database of 996 articles and partitioned it into two sets: one set from November 1, 2006, to September 7, 2007, and another set from September 8, 2008, to October 31, 2008 (i.e., one year "before" and "after" the first report of our study in the media). We first conducted a word frequency search on these articles and found that the word design occurred more frequently in the after-period compared to the before-period, such that its rank improved to 68 from 306. Specifically, the term design appeared 54 times (in 485 articles) before the publication of our study, and 233 times after (in 511 articles) - that is, over four times more occurrences.

To further ascertain that this shift was associated with the broader shifts in the discourse, we analyzed the titles of these media articles for word usage and sentiment. We noted that the vocabulary used in the articles became more diverse in the after-period relative to the beforeperiod. Specifically, the 511 article titles in the after-period were comprised of 3,204 total words and contained 1,083 different words. In contrast, the 485 titles in the before-period contained 856 different words and 2,970 total words. The top 50 words accounted for $47.34 \%$ of all words before and $41.33 \%$ after, indicating that the discourse was limited before and expanded after; it should be noted that these counts exclude the common words such as $a$, an, and the omitted by NVivo software. 
To examine the shift in trends, we conducted sentiment analysis on the titles and found that negative words decreased and positive words increased. Specifically, $84 \%$ of title words were negative in the before-period and $70 \%$ in the after-period, while positive words were $16 \%$ in the before-period and $30 \%$ in the after-period.

We then performed a word search query on the titles used before and after. Among the 50 most-used words in titles, we identified 11 words as negative and tracked their usage, both before and after. Of these, nine words lost their rank, with the word scandal losing as many as 238 spots and alert losing 213 spots. Other words that lost their prominence rank were crisis, scare, problems, concern, toxic, warns, and fears. Two words - danger and tainted-actually gained prominence. We analyzed their usage before and after and found that in the before-period, the word danger was used in conjunction with China (or low-cost outsourcing, 5 out of 13), with recalled toys in general (6 out of 13), with description of a specific recall (1), and with ineffective safety laws (1). In contrast, in the after-period, danger was not associated with China in a single headline, and its usage was more often used to described dangers of specific toys recalled (4), tips to avoid dangerous toys while shopping (4), safety groups warning of specific toys being dangerous (3), safety agency cautioning importers (2), and others. In other words, the word danger was earlier associated with China and toys in general, but such usage, particularly in reference to China, disappeared later on. Further, the use of the word tainted increased because it was primarily used to describe specific recalls involving lead and to refer to the 2007 recalls in general. In short, the word frequency analysis on all articles and the analysis of article titles revealed that a shift had occurred towards design issues as the source of the problem, and a more balanced and positive tone emerged in the discourse related to toy recalls. 
To examine the shift specifically with respect to design flaws as a reason for recalls (i.e., the subject of our study findings), we decided to focus on the news articles that used the word design at least once and conducted a word frequency search on these. We present the word frequency ranks in Table 2 and discuss our further analysis below.

Please insert Table 2 about here

In Table 2, we presented the top 30 words in the periods before and after. The relative rank by use of a number of words (e.g., toys, China, recall, products, Mattel, 2007, lead, and consumers) remained the same before and after, while a few showed little or no change (e.g., new, times, standards, million, last, safety, and quality). To determine the reasons for the shift in usage of the words that showed large differences in their usage rank, we examined the usage of these words before and after, with the help of text search queries on these words. We note the reason for the shift in the comment column in Table 2.

We found a reduction in discussions of factories, lead, and magnet toys. As a result, the occurrence of the word commission also declined because the pressure on safety commissions (e.g., Consumer Product Safety Commission) to monitor the imports from China decreased as the responsibility of MNEs became more prominent in the discourse. On the other hand, discussion of design and design problems increased, as well as discussion on world trade, exports, China, and Mattel. Interestingly, the words report and business gained prominence partly because our study was referred to as a "report" and we were referred to as "business professors."

Closer examination of the use of the word design revealed that any references before the publication of our study were limited to (i) identifying some recalls as those caused by design flaws, either by reporters or product safety advocates and industry insiders, and (ii) Chinese 
media outlets, which suggested that the magnet recalls were caused by brand owners' designs and not by manufacturers in China.

Following the publication of our study, the references to design were much more expansive. Some appeared in the context of discussing our study findings, Mattel's avoidance of responsibility for its design flaws, and Mattel's apology. Also, some articles discussed the undue finger-pointing at China, even when the problems were design flaws; in other instances, the CPSC clarified that certain recalls were due to design flaws.

After the discussion on Mattel's episode subsided, design was used to discuss a range of MNE behaviors and challenges, including the difficulties in identifying design flaws, moving towards simpler designs less prone to breakage, companies dictating stricter tests and design standards to contract manufacturers, thousands of workers in China being trained to identify design defects, creating of design jobs by companies, companies assuring that their design processes are stringent and asserting the role of better designs in their success, companies redesigning toys to discourage children from ingesting them and to better secure small parts, toy industry developing standards to prevent design flaws in magnetic toys and recommending third-party certifications of designs, companies partnering with testing agencies to improve designs, and the establishment of a design, innovation and production base for high-tech toys in China.

In addition to examining the newspaper articles, we also examined the statements made by the regulatory agencies in the US, China, and Europe, and we found that design became an area of focus in their discussions and communications. For example, the joint statements of meetings between the regulators of US and China prominently mentioned the need to improve 
designs, whereas those before our publications focused on improving manufacturing processes in China.

\section{Our role in the shift in discourse}

Our analysis of the word frequencies and our observations based on text search (presented in Table 2) are indicative of the shift in discourse, but we must point out that it is not possible to confidently draw conclusions based only on the usage patterns of single words. Further, these word usages do not indicate whether our research has played a role in the shift in discourse or whether a similar study unknown to us might have contributed. To rule out this possibility and to increase our confidence in the shift we noted in Table 2, we conducted a search using combinations of different words occurring in close proximity to each other.

Specifically, we examined the occurrence of a number of words related to China and manufacturing (i.e., China, problem, lead, paint, manufacturing, risk, defect, problem, quality) and Mattel and designs (i.e., Mattel, problem, and design) to see their frequency of occurrence within a 10-word proximity (denoted by $\sim 10$ ). We also examined the occurrence of design problem-related words (e.g., design, defect, problem, and flaw) as well as research-related words with design (e.g., design, study, research, university, expert, examine, studied) to see the pattern of usage for design problems and also to find out whether other researchers might have studied the same issue and communicated their findings. For each of the search queries, we studied their occurrences in the articles to understand the meaning of their usage. We present the results of these searches in Table 3 and briefly discuss below.

Please insert Table 3 about here 
As presented in Table 3, before the publication of our study, the discussion centered on systemic problems in China and lead paint, later shifting to a focus on designs and Mattel's conduct in the product safety crisis. Interestingly, although the focus was on China and lead, manufacturing and its associated problems were not discussed at length in the before-period. The increase in occurrence of manufacturing in the after-period was related to contrasting it with design flaws. Discussion of design flaws increased, fuelled first by our study and later by Mattel's apology. Further, perceptions of the problems faced by Mattel shifted from China and lead to design problems and a host of other problems (e.g., problems with regulators and supply chain monitoring). Also, the appearance of the words Mattel and design together in the beforeperiod was related to Mattel's recall involving magnets as a design flaw, later shifting to a discussion of our study and then a discussion of Mattel's apology in the after-period. Finally, nearly all references to design in the context of research, study, and university (in the proximity of 10 to 50 words) were connected to our research, thereby confirming that only our research, and not any other research, had likely contributed to the shift in the discourse. 
Table 2: Change in Word Usage - Before and After Publication of Bapuji \& Beamish (2007)

\begin{tabular}{|c|c|c|c|c|}
\hline \multirow{2}{*}{ Word } & \multicolumn{3}{|c|}{ Usage Rank } & \multirow{2}{*}{ Shift in Usage and Reasons } \\
\hline & Before & After & Gain/Loss & \\
\hline Toys & 1 & 1 & 0 & \\
\hline China & 2 & 2 & 0 & \\
\hline Recall & 3 & 3 & 0 & \\
\hline Products & 4 & 4 & 0 & \\
\hline Mattel & 5 & 5 & 0 & \\
\hline Company & 6 & 8 & -2 & \\
\hline Safety & 7 & 10 & -3 & \\
\hline Magnets & 8 & 19 & -11 & $\begin{array}{l}\text { Decreased focus on magnets, but decrease is less due } \\
\text { to use of 'magnets' as an example of design flaws }\end{array}$ \\
\hline 2007 & 9 & 9 & 0 & \\
\hline made & 10 & 6 & 4 & \\
\hline Lead & 11 & 11 & 0 & \\
\hline Paint & 12 & 18 & -6 & \\
\hline Manufacturing & 13 & 7 & 6 & $\begin{array}{l}\text { Shift not noticeable as manufacturing was used in the } \\
\text { after-period to contrast design with manufacturing }\end{array}$ \\
\hline Million & 14 & 16 & -2 & \\
\hline Factories & 15 & 61 & -46 & Decreased focus on factories making goods \\
\hline Children & 16 & 24 & -8 & \\
\hline Consumers & 17 & 17 & 0 & \\
\hline Quality & 18 & 14 & 4 & \\
\hline Industry & 19 & 21 & -2 & \\
\hline Year & 20 & 13 & 7 & \\
\hline New & 21 & 20 & 1 & \\
\hline Brands & 22 & 30 & -12 & $\begin{array}{l}\text { Decreased discussion on MNC reputation losses due } \\
\text { to recalls }\end{array}$ \\
\hline Tests & 23 & 45 & -22 & Decreased focus on tests for excess lead \\
\hline Times & 24 & 23 & 1 & \\
\hline Design & 25 & 12 & 13 & Increased discussion of design \\
\hline Standards & 26 & 25 & 1 & \\
\hline Problems & 27 & 15 & 12 & Increased use with design, i.e., 'design problem' \\
\hline Commission & 28 & 120 & -92 & Decreased focus on safety commission \\
\hline Swallowing & 29 & 81 & -52 & $\begin{array}{c}\text { Decreased focus on the danger of swallowing } \\
\text { magnets in toys }\end{array}$ \\
\hline Use & 30 & 53 & -23 & $\begin{array}{l}\text { Different use; used with lead in the before-period } \\
\text { and with magnets in the after-period }\end{array}$ \\
\hline Exports & 37 & 22 & 15 & Increased discussion on China's exports and trade \\
\hline Business & 69 & 26 & 42 & Increased focus on business aspects; also on B\&B \\
\hline Report & 39 & 27 & 12 & $\begin{array}{c}\text { Increased reporting of safety incidents; also B\&B } \\
\text { referred as report }\end{array}$ \\
\hline Last & 32 & 28 & 4 & \\
\hline World & 81 & 29 & 52 & $\begin{array}{l}\text { Increased discussion on positions of China (e.g., } \\
\text { World's toy factory), Mattel (e.g., World's leading }\end{array}$ \\
\hline
\end{tabular}




\begin{tabular}{|c|l|l|l|l|}
\hline & & & & toy company) \\
\hline
\end{tabular}

Note: B\&B refers to Bapuji and Beamish, both to the study and to their views mentioned in the news articles. 
Table 3: Change in Discourse - Before and After Publication of Bapuji \& Beamish (2007)

\begin{tabular}{|c|c|c|c|}
\hline \multirow{2}{*}{ Query } & \multicolumn{2}{|c|}{ Number \& Coverage } & \multirow{2}{*}{ Shift in Usage and Reason } \\
\hline & Before & After & \\
\hline \multicolumn{4}{|c|}{ Discussion on Systemic Problems in China Shifted to Broader Discussion and Mattel's Role } \\
\hline "China problem" $\sim 10$ & $44(0.18 \%)$ & $54(0.18 \%)$ & \multirow{2}{*}{$\begin{array}{l}\text { Systemic problem in China } \rightarrow \\
\text { mixed, including design }\end{array}$} \\
\hline "Chinese problem" $\sim 10$ & $34(0.19 \%)$ & $28(0.11 \%)$ & \\
\hline "China lead" $\sim 10$ & $229(0.87 \%)$ & $187(0.72 \%)$ & \multirow{4}{*}{$\begin{array}{l}\text { Lead paint problem } \rightarrow \text { less focus on } \\
\text { China, discussion of design flaws and } \\
\text { Mattel's conduct }\end{array}$} \\
\hline "Chinese lead" $\sim 10$ & $227(0.87 \%)$ & $160(0.68 \%)$ & \\
\hline "Chinese paint" $\sim 10$ & $202(0.75 \%)$ & $113(0.47 \%)$ & \\
\hline "China paint" $\sim 10$ & $186(0.76 \%)$ & $127(0.49 \%)$ & \\
\hline \multicolumn{4}{|c|}{ Despite Focus on China, Little Discussion on Manufacturing Itself } \\
\hline Manufacturing & $168(0.15 \%)$ & $238(0.21 \%)$ & Increase due to contrast with design \\
\hline "manufacturing defect" $\sim 10$ & $1(0.01 \%)$ & 0 & \\
\hline "manufacturing problem" & 0 & 2 & \\
\hline "manufacturing problem" 10 & 0 & $14(0.09 \%)$ & $\begin{array}{l}\text { In the context of discussing design } \\
\text { flaws, } 1 / 2 \text { by } B \& B\end{array}$ \\
\hline "manufacturing risk" $\sim 10$ & $2(0.01 \%)$ & $3(0.02 \%)$ & \\
\hline "manufacturing quality" $\sim 10$ & $24(0.12 \%)$ & $26(0.14 \%)$ & \\
\hline \multicolumn{4}{|c|}{ Increased Discussion of Design Flaws, Fuelled by Bapuji \& Beamish and Mattel Apology } \\
\hline Design & $54(0.02 \%)$ & $233(0.10 \%)$ & \\
\hline "design defect" & 0 & $5(0.01 \%)$ & Mattel apology discussion \\
\hline "design problem" & 0 & $1(0.01 \%)$ & \\
\hline "design defect" $\sim 10$ & 0 & $7(0.01 \%)$ & Recall causes \\
\hline "design problem" $\sim 10$ & $5(0.02 \%)$ & $18(0.07 \%)$ & Mattel recall $\rightarrow$ Nearly all by B\&B \\
\hline "design flaw" & $5(0.01 \%)$ & $20(0.01 \%)$ & \multirow{2}{*}{$\begin{array}{l}\text { Mattel recall } \rightarrow \text { some } \mathrm{B} \& \mathrm{~B}, \text { some } \\
\text { apology }\end{array}$} \\
\hline "design flaw" $\sim 10$ & $5(0.01 \%)$ & $27(0.05 \%)$ & \\
\hline \multicolumn{4}{|c|}{ Perceptions About Mattel's Problem Shifted from China to its own Designs and its Role } \\
\hline "Mattel problem" $\sim 10$ & $65(0.28 \%)$ & $28(0.12 \%)$ & China/lead $\rightarrow$ design, mixed \\
\hline "Mattel design" $\sim 10$ & $14(0.06 \%)$ & $82(0.33 \%)$ & $\begin{array}{l}\text { Mattel recall } \rightarrow \text { some } \mathrm{B} \& \mathrm{~B} \text {, many to } \\
\text { apology }\end{array}$ \\
\hline \multicolumn{4}{|c|}{ All References to Research on Design Flaws are to Bapuji \& Beamish Study } \\
\hline "design study" $\sim 10 \& \sim 50$ & 0 & $11(0.05 \%)$ & \multirow{3}{*}{ All references to $\mathrm{B} \& \mathrm{~B}$} \\
\hline "design research" $\sim 10$ & 0 & $5(0.02 \%)$ & \\
\hline "design research" $\sim 50$ & 0 & $7(0.09 \%)$ & \\
\hline "design university" $\sim 50$ & $1(0.01 \%)$ & $15(0.36 \%)$ & $\begin{array}{l}14 \text { out of } 15 \mathrm{~B} \& \mathrm{~B} \text {; rest not related to } \\
\text { any research study }\end{array}$ \\
\hline "design expert" $\sim 50$ & 0 & $2(0.04 \%)$ & \multirow{4}{*}{$\begin{array}{l}\text { Unrelated occurrences; words appear } \\
\text { in different sentences }\end{array}$} \\
\hline "recall research" $\sim 10$ & 0 & $3(0.01 \%)$ & \\
\hline "recall examine" $\sim 10$ & 0 & $1(0.01 \%)$ & \\
\hline "recall studied" $\sim 10$ & 0 & $1(0.01 \%)$ & \\
\hline
\end{tabular}

